\title{
DEVELOPMENT OF MATHEMATICAL MODELS TO ANALYSE AND PREDICT WELD BEAD GEOMETRY AND SHAPE RELATIONSHIPS IN GMA WELDING OF C-45 STEEL
}

\author{
Shubham Jain ${ }^{1}$, Paritosh Singhal ${ }^{2}$, Pradeep Khanna ${ }^{3}$ \\ ${ }^{1}$ Student, Netaji Subhas Institute of Technology \\ ${ }^{2}$ Student, Netaji Subhas Institute of Technology \\ ${ }^{3}$ Associate Professor, Netaji Subhas Institute of Technology
}

\begin{abstract}
Gas Metal Arc Welding (GMAW) has proved its significance in fabrication industry owing to its versatility and quality of joints. The process lends itself to full automation further increasing its potential use in mass production industry. To make the process automatic, it is necessary to establish relationship between the input parameters and the desired output. In the present case,effect of input parameters like Wire Feed Rate (WFR), Voltage, Welding Speed, Torch Angle, Nozzle to Plate distance(NPD) has been investigated on bead geometry and shape relationship responses like Penetration, Width, Height of Reinforcement, Weld dilution ,Weld Penetration Shape Factor(WPSF),Weld Reinforcement Form Factor (WRFF).Statistical approach of design of experiments has been used to conduct the experiments. Response surface methodology technique has been used to optimize the results. Mathematical model has thus been developed whose significance and fitness has been checked by using design expert software.
\end{abstract}

Keywords: - Arc welding, input parameters, bead geometry, mathematical modelling, response surface methodology $* * *$

\section{INTRODUCTION}

Gas Metal Arc Welding (GMAW) is a welding process in which an electric arc forms between a consumable wire electrode and the workpiece metal, which heats the workpiece metal, causing them to melt and join. It is one of the most fundamental and most applied processes in a manufacturing industry amongst the various other manufacturing processes. With the growing demand and applications of automated welding systems, GMAW is employed in semi-automatic as well as automatic mode in the present industry. The present research work is aimed to carry out elaborated investigative work to study and analyze the effect of weld parameters on various response parameters such as depth of penetration (P), height of reinforcement $(\mathrm{H})$, weld width $(\mathrm{W})$, weld dilution which is defined as the ratio of penetration area to the total bead area $\left(A_{P} / A_{T}\right)$, weld penetration shape factor (WPSF) is defined as the ratio of weld width to the depth of penetration (W/P), weld reinforcement form factor (WRFF) is defined as the ratio of weld width to the height of reinforcement $(\mathrm{W} / \mathrm{H})$.
A common problem that has faced the fabricators is the control of the process input parameters to obtain a good welded joint with the required bead geometry [1] Conventionally, this is done by conducting trial experiments with different values of input parameters to reach to the desired bead geometry. This not only is a crude method, sometimes involving a lot of steps and still not getting desired results. Secondly it also cannot predict the effect of change of various parameters of bead geometry. The prediction and optimization of process parameters, therefore is an important aspect in welding process [2].This includes analyzing information on effects of input parameters on weld bead quality parameters and finding out the relationship between them [3].

C45 steel is a popular structural steel extensively used in buildings, frames and marine applications [4].The chemical composition and mechanical properties of this steel are given in table 1 and table 2 respectively.

Table 1: chemical composition of C45 [Ref. 5]

\begin{tabular}{|l|l|l|l|l|l|l|l|l|l|}
\hline Element & C & Si & Mn & P & S & Cr & Mo & Ni & Cr+Mo+Ni \\
\hline Chemical & $0.42-$ & $<0.40$ & $0.50-$ & $<0.045$ & $<0.045$ & $<0.40$ & $<0.10$ & $<0.40$ & $<0.63$ \\
Composition & 0.50 & & 0.80 & & & & & & \\
\hline
\end{tabular}

Table 2: Mechanical Properties of C45 [Ref. 5]

\begin{tabular}{|l|l|}
\hline $0.2 \%$ proof stress $\left(\mathrm{R}_{\mathrm{p}}\right) \mathrm{N} / \mathrm{mm}^{2}$ & Min.490 \\
\hline Tensile strength $\left(\mathrm{R}_{\mathrm{m}}\right) \mathrm{N} / \mathrm{mm}^{2}$ & $750-850$ \\
\hline Fracture Elongation $\left(\mathrm{A}_{\mathrm{s}}\right) \%$ & Min. 14 \\
\hline
\end{tabular}




\begin{tabular}{|l|l|}
\hline Reduction of Area (Z) \% & Min. 35 \\
\hline
\end{tabular}

Research carried out by various researchers [6-9] has shown that even a small change in any of the input parameters could have a major effect on different bead geometry parameters.

\section{EXPERIMENTAL SETUP}

The experimental setup for the present investigation work is shown in figure 1.

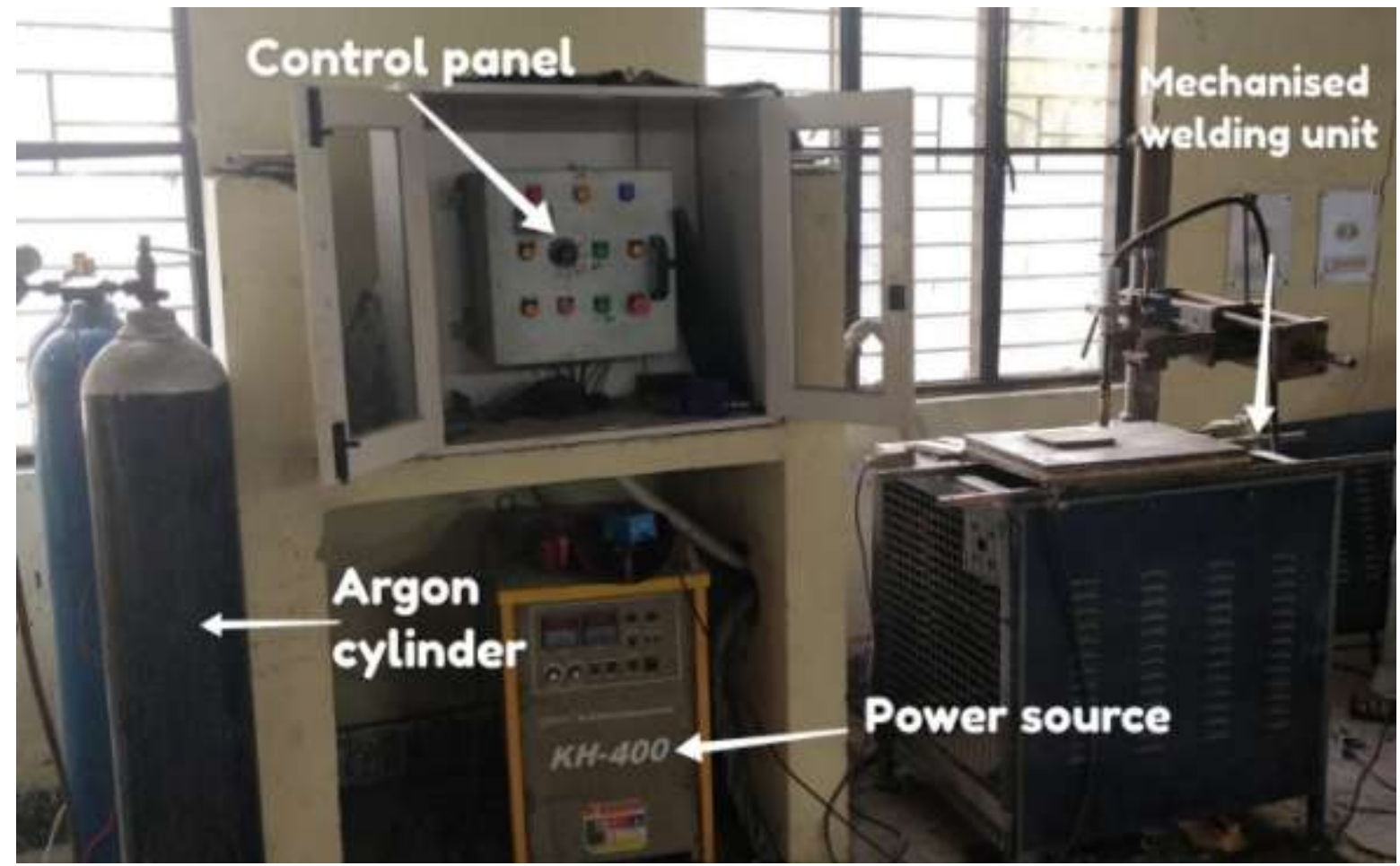

Fig 1: The experimental setup

The setup consists of a flat characteristic V-I power source with rated current capacity of 400 Amps. A mechanized welding unit is used which a facility to impart different welding speeds has required for the investigation. Tis not only resulted in consistency in welds but also gave good quality weld bead. This unit was controlled by a dedicated control panel which has the facility of setting different speed steplessly and also of motion reversal.

\section{PLAN OF INVESTIGATION}

- Identifying the important process parameters and their operating ranges

- Developing the design matrix

- Conducting the experiments as per the design matrix

- Development of mathematical models

- Testing the significance of the developed model and regression coefficients

- Results and their discussion

- Conclusions

\subsection{Identifying the Important Process Parameters and their Operating Ranges}

A series of trial experiments were conducted to identify important process parameters. It was found that voltage (V), wire feed rate $(\mathrm{m} / \mathrm{min})$, welding speed $(\mathrm{cm} / \mathrm{min})$, nozzle to plate distance $(\mathrm{mm})$ and torch angle (degrees). In order to ascertain the operating limits of these parameters, further trials runs were carried out and the operating limits were decided keeping following points in view.

a. The weld bead has good appearance

b. There are no visible cracks

c. No spatters and undercuts

The lower limits of process parameters are indicated by -2 and the higher limits were indicated by +2 , with intermediate values as $-1,0,+1$. These values are shown in table 3.

Table 3: Process parameters and their limits 


\begin{tabular}{|l|l|l|l|l|l|l|}
\hline Process parameters & Units & $\mathbf{- 2}$ & $\mathbf{- 1}$ & $\mathbf{0}$ & $\mathbf{+ 1}$ & $\mathbf{+ 2}$ \\
\hline Voltage & $\mathrm{V}$ & 14 & 16 & 18 & 20 & 22 \\
\hline Wire feed rate & $\mathrm{m} / \mathrm{min}$ & 0.3 & 0.6 & 0.9 & 1.2 & 1.5 \\
\hline Nozzle to plate distance & $\mathrm{Mm}$ & 10 & 13 & 16 & 19 & 22 \\
\hline Torch angle & degrees & 70 & 80 & 90 & 100 & 110 \\
\hline Welding speed & $\mathrm{cm} / \mathrm{min}$ & 25 & 30 & 35 & 40 & 45 \\
\hline
\end{tabular}

\subsection{Developing the Design Matrix}

Once the operating limits of the parameters were decided, experiments were conducted using the combination given in design matrix shown in table 4 . The total of 32 experiments were conducted $\left(2^{5-1}+2 * 5+6=32\right)$, consisting of 16 fraction factorial runs, 10 star points and 6 center points, as per the central composite rotatable design technique where each variable was varied at 5 levels indicated in table 3 .

\subsection{Conducting the Experiments as per the Design}

\section{Matrix}

32 number of welds were made using the combinations given in table 4 . The work piece of size $150 \mathrm{~mm}$ $* 125 \mathrm{~mm} * 6 \mathrm{~mm}$ were used for bead on plate technique. Each welded piece was cut from the middle to have a specimen size of $60 \mathrm{~mm} * 30 \mathrm{~mm} * 6 \mathrm{~mm}$. These pieces were then polished using standard polishing techniques and were then etched using the recommended etchant Nital solution. The prepared specimen were checked by using Imagej software. The actual photograph of one of the specimen is given in fig2.

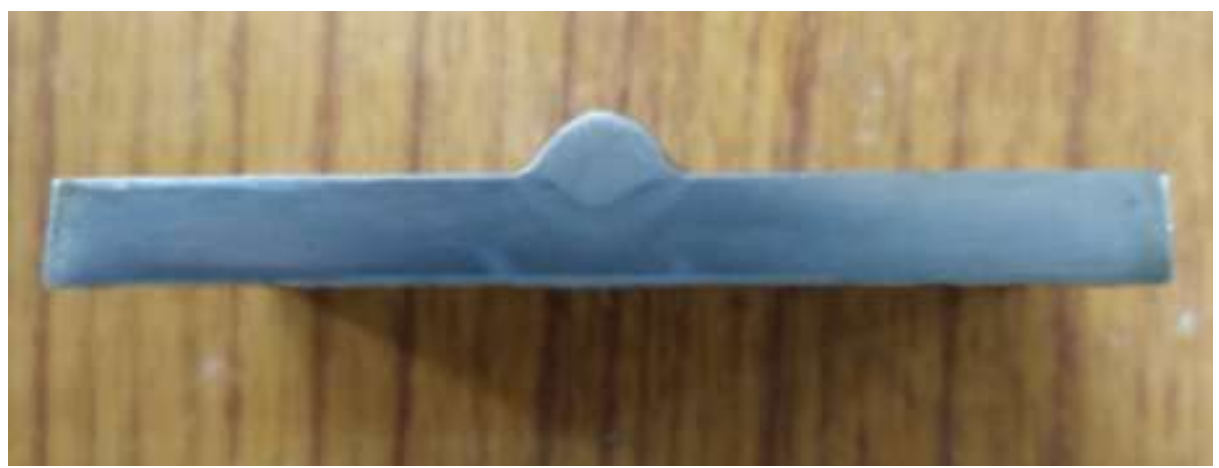

Fig 2: Photograph of a real weld bead

The same software also facilitated the measurement of depth of penetration, weld width, height of reinforcement and area of the bead cross section. These parameters were then used to calculate the values of WPSF which is the ratio of width and penetration, WRFF which is the ratio of width and reinforcement, and finally the dilution which is the ratio of area of penetration and the total area of bead. All these values are recorded in table 4.

\subsection{Development of Mathematical Models}

The dependence of output parameters on the input factors can be shown as

$$
y=f(A, B, C, D, E)
$$

Where $\mathrm{A}=$ Voltage $(\mathrm{V}), \mathrm{B}=$ Wire feed rate $(\mathrm{m} / \mathrm{min})$, $\mathrm{C}=$ Welding speed $(\mathrm{cm} / \mathrm{min}), \mathrm{D}=$ Torch angle (degrees), $\mathrm{E}=$ Nozzle to plate distance $(\mathrm{mm})$
The general regression equation for the model can be given as below:

$$
\beta_{0}+\beta_{1} \mathrm{~A}+\beta_{2} \mathrm{~B}+\beta_{3} \mathrm{C}+
$$

$\beta_{4} \mathrm{D}+\beta_{5} \mathrm{E}+\beta_{12} \mathrm{AB}+\beta_{13} \mathrm{AC}+\beta_{14} \mathrm{AD}+\beta_{15} \mathrm{AE}+\beta_{23} \mathrm{BC}+\beta_{24} \mathrm{BD}+$ $\beta_{25} \mathrm{BE} \quad \beta_{34} \mathrm{CD}+\beta_{35} \mathrm{CE}+\beta_{45} \mathrm{DE} \quad \beta_{11} \mathrm{~A}^{2}+\beta_{22} \mathrm{~B}^{2}+\beta_{33} \mathrm{C}^{2}+\beta_{44} \mathrm{D}^{2}$

$$
+\beta_{55} \mathrm{E}^{2}
$$

Where $\mathrm{Y}$ is the response parameter $\beta_{0}$ is the coefficient of the model, $\beta_{1} \ldots . \beta_{5}$ are the coefficients of linear terms, $\beta_{12} \ldots \beta_{45}$ are the coefficients of interaction terms, $\beta_{11} \ldots . . \beta_{55}$ are the coefficients of square terms.

Design expert software was used for the development of mathematical models for the response parameters. The mathematical equations developed by the use of this software for different response parameters are given in the form of equations (1-6). 
Table 4: Design matrix and observed values of bead parameters

\begin{tabular}{|c|c|c|c|c|c|c|c|c|c|c|c|}
\hline Run & Voltage & WFR & $\begin{array}{l}\text { Welding } \\
\text { speed }\end{array}$ & $\begin{array}{l}\text { Torch } \\
\text { angle }\end{array}$ & $\begin{array}{l}\mathrm{NP} \\
\mathrm{D}\end{array}$ & Penetration & Width & Height & $\begin{array}{l}\text { Weld } \\
\text { dilution }\end{array}$ & $\begin{array}{l}\text { WPS } \\
\text { F }\end{array}$ & $\begin{array}{l}\text { WRF } \\
\text { F }\end{array}$ \\
\hline & volt & $\begin{array}{l}\mathrm{m} / \\
\mathrm{min}\end{array}$ & hertz & $\begin{array}{l}\text { degre } \\
\mathrm{e}\end{array}$ & $\mathrm{mm}$ & $\mathrm{mm}$ & $\mathrm{mm}$ & $\mathrm{mm}$ & $\%$ & & \\
\hline 1 & 20 & 6 & 40 & 80 & 19 & 1.40 & 7.05 & 1.63 & 44.60 & 5.03 & 4.39 \\
\hline 2 & 18 & 8 & 35 & 90 & 16 & 1.84 & 9.68 & 3.28 & 30.69 & 5.28 & 2.95 \\
\hline 3 & 18 & 8 & 35 & 90 & 16 & 2.04 & 9.44 & 3.19 & 33.44 & 4.62 & 2.95 \\
\hline 4 & 16 & 10 & 30 & 100 & 19 & 2.45 & 10.01 & 4.09 & 29.29 & 4.08 & 2.44 \\
\hline 5 & 18 & 8 & 35 & 90 & 16 & 1.80 & 10.42 & 3.34 & 34.34 & 5.78 & 3.11 \\
\hline 6 & 16 & 10 & 40 & 100 & 13 & 1.36 & 8.03 & 3.24 & 23.95 & 5.90 & 2.07 \\
\hline 7 & 18 & 8 & 35 & 90 & 10 & 2.18 & 8.29 & 3.60 & 29.75 & 3.80 & 2.49 \\
\hline 8 & 20 & 10 & 30 & 100 & 13 & 2.53 & 11.05 & 3.35 & 30.19 & 4.36 & 3.29 \\
\hline 9 & 18 & 12 & 35 & 90 & 16 & 2.04 & 7.84 & 3.88 & 24.94 & 5.83 & 2.48 \\
\hline 10 & 18 & 8 & 35 & 90 & 22 & 1.79 & 8.24 & 3.76 & 31.19 & 4.60 & 2.06 \\
\hline 11 & 16 & 6 & 30 & 80 & 19 & 1.36 & 8.78 & 3.34 & 18.87 & 6.45 & 2.62 \\
\hline 12 & 20 & 6 & 30 & 80 & 13 & 1.30 & 11.38 & 2.49 & 18.75 & 8.75 & 4.57 \\
\hline 13 & 18 & 8 & 45 & 90 & 16 & 1.63 & 7.17 & 2.91 & 37.16 & 4.39 & 2.55 \\
\hline 14 & 16 & 6 & 40 & 100 & 19 & 1.45 & 6.51 & 3.79 & 21.78 & 4.48 & 1.71 \\
\hline 15 & 16 & 6 & 40 & 80 & 13 & 1.26 & 8.12 & 2.66 & 29.66 & 6.44 & 3.05 \\
\hline 16 & 14 & 8 & 35 & 90 & 16 & 1.18 & 5.86 & 3.76 & 19.62 & 4.96 & 1.58 \\
\hline 17 & 18 & 8 & 35 & 70 & 16 & 1.98 & 9.90 & 3.00 & 34.61 & 5.00 & 3.30 \\
\hline 18 & 16 & 10 & 30 & 80 & 13 & 2.10 & 8.92 & 4.66 & 24.38 & 4.24 & 1.48 \\
\hline 19 & 18 & 8 & 35 & 90 & 16 & 1.92 & 8.63 & 3.05 & 35.78 & 4.49 & 2.83 \\
\hline 20 & 20 & 6 & 40 & 100 & 13 & 1.17 & 9.81 & 2.60 & 29.52 & 8.38 & 3.77 \\
\hline 21 & 20 & 10 & 40 & 100 & 19 & 2.07 & 9.64 & 3.93 & 25.96 & 4.66 & 2.45 \\
\hline 22 & 20 & 10 & 40 & 80 & 13 & 2.77 & 9.42 & 2.95 & 33.54 & 3.97 & 3.19 \\
\hline 23 & 18 & 8 & 35 & 90 & 16 & 1.84 & 9.68 & 3.28 & 30.69 & 5.29 & 2.95 \\
\hline 24 & 18 & 8 & 25 & 90 & 16 & 2.37 & 10.55 & 3.72 & 29.61 & 4.45 & 2.84 \\
\hline 25 & 16 & 10 & 40 & 80 & 19 & 0.97 & 6.35 & 3.46 & 15.18 & 6.55 & 1.84 \\
\hline 26 & 20 & 10 & 30 & 80 & 19 & 2.48 & 10.08 & 3.82 & 29.42 & 4.06 & 2.64 \\
\hline 27 & 18 & 8 & 35 & 110 & 16 & 2.05 & 9.67 & 3.36 & 32.71 & 4.71 & 2.88 \\
\hline 28 & 22 & 8 & 35 & 90 & 16 & 2.03 & 12.59 & 2.42 & 30.90 & 6.20 & 4.35 \\
\hline 29 & 16 & 6 & 30 & 100 & 13 & 2.04 & 9.23 & 2.83 & 31.28 & 4.52 & 3.26 \\
\hline 30 & 20 & 6 & 30 & 100 & 19 & 1.44 & 9.57 & 2.77 & 25.87 & 6.65 & 3.61 \\
\hline 31 & 18 & 4 & 35 & 90 & 16 & 0.56 & 7.36 & 1.84 & 27.17 & 11.18 & 4.47 \\
\hline 32 & 18 & 8 & 35 & 90 & 16 & 1.00 & 9.20 & 3.31 & 32.12 & 5.44 & 2.78 \\
\hline
\end{tabular}

(1) Penetration $=1.75+0.16 * \mathrm{~A}+0.34 * \mathrm{~B}-0.19 * \mathrm{C}+0.04 * \mathrm{D}-$ $0.07 * \mathrm{E}+0.24 * \mathrm{AB}+0.16 * \mathrm{AC}-0.15 * \mathrm{AD}+0.01 * \mathrm{AE}-0.09 * \mathrm{BC}-$ $0.04 * \mathrm{BD}-0.04 * \mathrm{BE}-0.10 * \mathrm{CD}-0.03 * \mathrm{CE}+0.10 * \mathrm{DE}-0.04 * \mathrm{~A}^{2}-$ $0.12 * \mathrm{~B}^{2}+0.06 * \mathrm{C}^{2}+0.06 * \mathrm{D}^{2}+0.05 * \mathrm{E}^{2}$

(2) Width $=9.51+1.68 * \mathrm{~A}+0.12 * \mathrm{~B}-0.84 * \mathrm{C}-0.06 * \mathrm{D}-$ $0.01 * \mathrm{E}+0.11 * \mathrm{AB}+0.11 * \mathrm{AC}+0.03 * \mathrm{AD}-$

$0.17 * \mathrm{AE}+0.05 * \mathrm{BC}+0.26 * \mathrm{BD}+0.33 * \mathrm{BE}+0.15 * \mathrm{CD}-$ $0.23 * \mathrm{CE}+0.20 * \mathrm{DE}-0.07 * \mathrm{~A}^{2}-0.48 * \mathrm{~B}^{2}-0.16 * \mathrm{C}^{2}+0.07 * \mathrm{D}^{2}-$ $0.31 * \mathrm{E}^{2}$

(3) Reinforcement $=3.24-0.30 * \mathrm{~A}+0.48 * \mathrm{~B}-0.20 * \mathrm{C}+$ $0.10 * \mathrm{D}+0.10 * \mathrm{E}+0.11 * \mathrm{AB}+0.03 * \mathrm{AC}+0.12 * \mathrm{AD}-0.03 * \mathrm{AE}-$ $0.10 * \mathrm{BC}-$

$0.13 \mathrm{~B} * \mathrm{BD}+0.01 * \mathrm{BE}+0.26 * \mathrm{CD}+0.04 * \mathrm{CE}+0.19 * \mathrm{DE}-$ $0.04 * \mathrm{~A}^{2}-0.09 * \mathrm{~B}^{2}+0.02 * \mathrm{C}^{2}-0.01 * \mathrm{D}^{2}+0.11 * \mathrm{E}^{2}$
(4) Weld dilution $=33.21+2.75 * \mathrm{~A}-0.54 * \mathrm{~B}+1.30 * \mathrm{C}-0.01 * \mathrm{D}$ $0.31 * \mathrm{E}+0.57 * \mathrm{AB}+2.66 * \mathrm{AC}-2.06 * \mathrm{AD}+2.37 * \mathrm{AE}-$

$2.84 * \mathrm{BC}+0.64 * \mathrm{BD}-0.88 * \mathrm{BE}-2.93 * \mathrm{CD}-0.50 * \mathrm{CE}-0.86 * \mathrm{DE}-$ $2.26 * \mathrm{~A}^{2}-2.06 * \mathrm{~B}^{2}-0.23 * \mathrm{C}^{2}-0.16 * \mathrm{D}^{2}-0.95 * \mathrm{E}^{2}$

(5) $\mathrm{WPSF}=5.17+0.24 * \mathrm{~A}-0.98 * \mathrm{~B}+0.09 * \mathrm{C}-0.12 * \mathrm{D}-0.13 * \mathrm{E}-$ $0.66 * \mathrm{AB}-0.37 * \mathrm{AC}+0.43 * \mathrm{AD}$

$0.35 * \mathrm{AE}+0.39 * \mathrm{BC}+0.17 * \mathrm{BD}+0.39 * \mathrm{BE}+0.33 * \mathrm{CD}-$

$0.21 * \mathrm{CE}-0.12 * \mathrm{DE}+0.09 * \mathrm{~A}^{2}+0.82 * \mathrm{~B} \quad-0.19 * \mathrm{C}^{2}-0.08 * \mathrm{D}^{2}-$ $0.25 * \mathrm{E}^{2}$

(6) $\mathrm{WRFF}=2.93+0.62 * \mathrm{~A}-0.48 * \mathrm{~B}-0.08 * \mathrm{C}-0.08 * \mathrm{D}-0.16 * \mathrm{E}-$ $0.12 * \mathrm{AB}+0.05 * \mathrm{AC}-0.13 * \mathrm{AD}$ $0.03 * \mathrm{AE}+0.0 * \mathrm{BC}+0.21 * \mathrm{BD}+0.10 * \mathrm{BE}-0.23 * \mathrm{CD}-0.02 * \mathrm{CE}-$ $0.08 * \mathrm{DE}+0.01 * \mathrm{~A}^{2}+0.14 * \mathrm{~B}^{2}-0.06 * \mathrm{C}^{2}+0.04 * \mathrm{D}^{2}-0.16 * \mathrm{E}^{2}$ 


\subsection{Testing the Significance of the Developed Model and Regression Coefficients}

Significance of the developed models was checked by Analysis of variance (ANOVA) technique. This analysis was also conducted by design expert software and the results are consolidated for the six response parameter in table 5. It is evident from the table that all the developed models are significant. The significance of the coefficients can be ascertained from the values of lack of fit which in all the cases was found to be not significant as shown in table 5 . Further the scatter diagrams for all the response parameters indicate a close proximity between the actual and the predicted values. To keep the reporting work within reasonable limits only two scatter diagrams are shownin figure 3,4 .

Table 5: Testing the significance of model

\begin{tabular}{|l|l|l|l|l|l|l|l|l|l|l|l|l|}
\hline & \multicolumn{9}{|l}{ SIGNIFICANCE OF MODEL } & \multicolumn{1}{l|}{ LACK OF FIT } \\
\hline & SS & df & MS & $\begin{array}{l}\text { F- } \\
\text { Value }\end{array}$ & $\begin{array}{l}\text { P- } \\
\text { Value }\end{array}$ & $\begin{array}{l}\text { Whether } \\
\text { significant }\end{array}$ & SS & df & MS & $\begin{array}{l}\text { F- } \\
\text { Value }\end{array}$ & $\begin{array}{l}\text { P- } \\
\text { Value }\end{array}$ & $\begin{array}{l}\text { Whether } \\
\text { significant }\end{array}$ \\
\hline Penetration & 7.54 & 20 & 0.37 & 5.49 & 0.003 & YES & 0.06 & 6 & 0.01 & 0.07 & 0.99 & NO \\
\hline Width & 61.69 & 20 & 3.08 & 3.79 & 0.013 & YES & 7.20 & 6 & 1.20 & 3.41 & 0.09 & NO \\
\hline Height & 12.35 & 20 & 0.62 & 54.14 & 0.0001 & YES & 0.06 & 6 & 0.01 & 1.01 & 0.50 & NO \\
\hline $\begin{array}{l}\text { Weld } \\
\text { Dilution }\end{array}$ & 1076.55 & 20 & 53.83 & 11.76 & 0.0001 & YES & 29.27 & 6 & 4.88 & 1.16 & 0.44 & NO \\
\hline WPSF & 73.08 & 20 & 3.65 & 9.41 & 0.0003 & YES & 3.04 & 6 & 0.50 & 2.05 & 0.22 & NO \\
\hline WRFF & 19.97 & 20 & 0.99 & 64.42 & 0.0001 & YES & 0.10 & 6 & 0.01 & 1.18 & 0.43 & NO \\
\hline
\end{tabular}

Where, $\mathrm{SS}=$ sum of squares, $\mathrm{df}=$ degree of freedom, $\mathrm{MS}=$ mean square

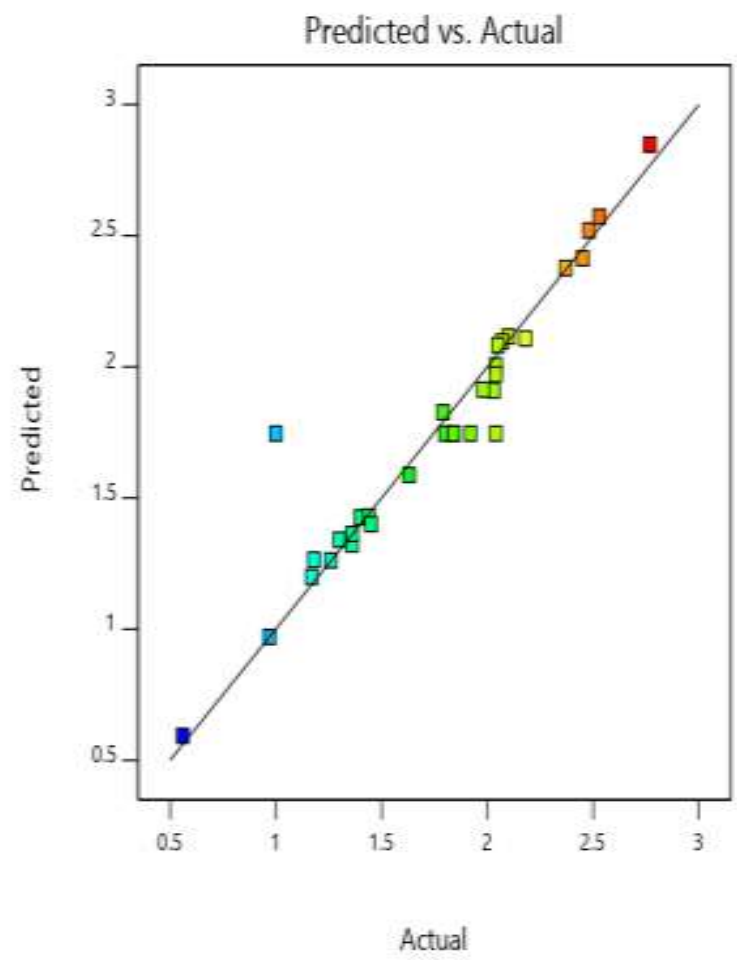

Fig.3: Scatter diagram for Penetration

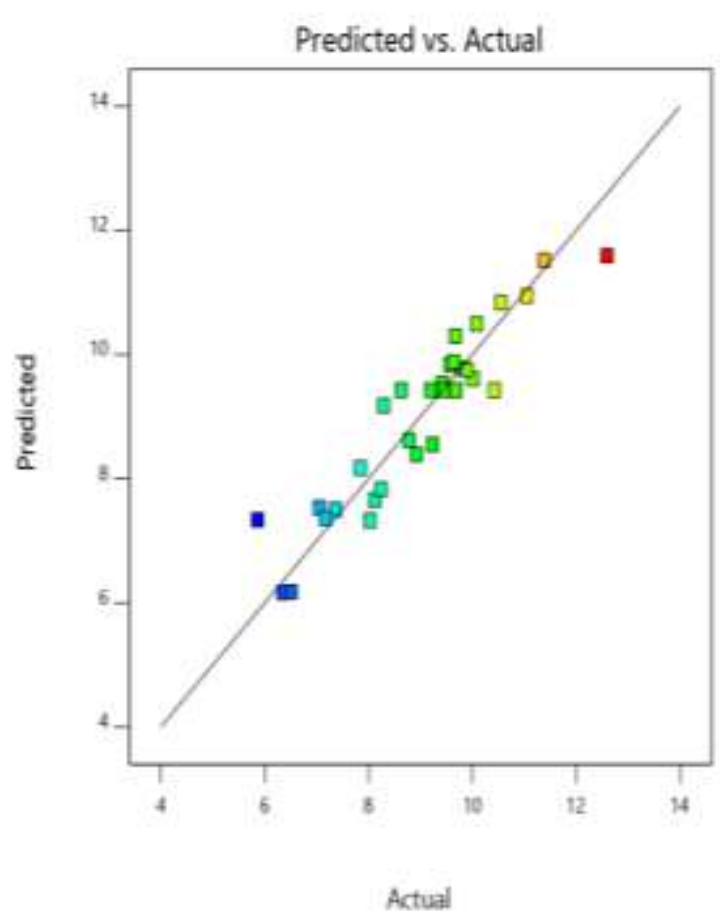

Fig.4: Scatter diagram for Width

\subsubsection{Direct Effects of Input Parameters}

Direct effects are those where one parameter is changed over its working range while the others are kept constant at some intermediate level. The results so obtained are discussed as follows 


\subsubsection{Direct Effect of Voltage}

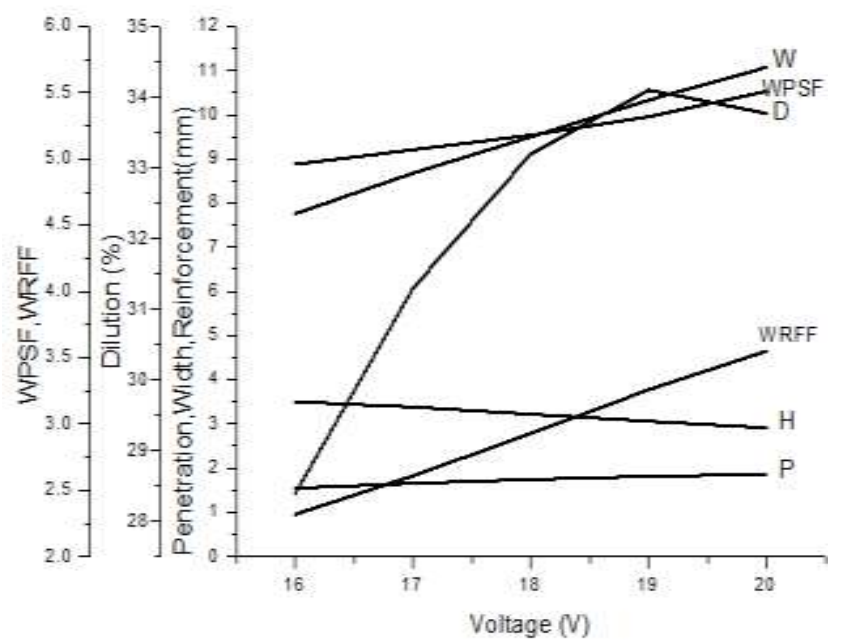

Fig 5: Direct effect of voltage

It is evident from fig 5 that voltage has positive effect on width whereas a negative effect on penetration and reinforcement. The explanation for such results is that with the increase in voltage the spreading effect of arc increased which led to wider bead at higher voltages. With the increase in arc spread the penetration and reinforcement were reduced as the total cross section of the bead remained the same. Dilution, WPSF and WRFF being the ratios of prime parameters like penetration, width and reinforcement, their change pattern can be explained accordingly.

\subsubsection{Direct Effect of Wire Feed Rate}

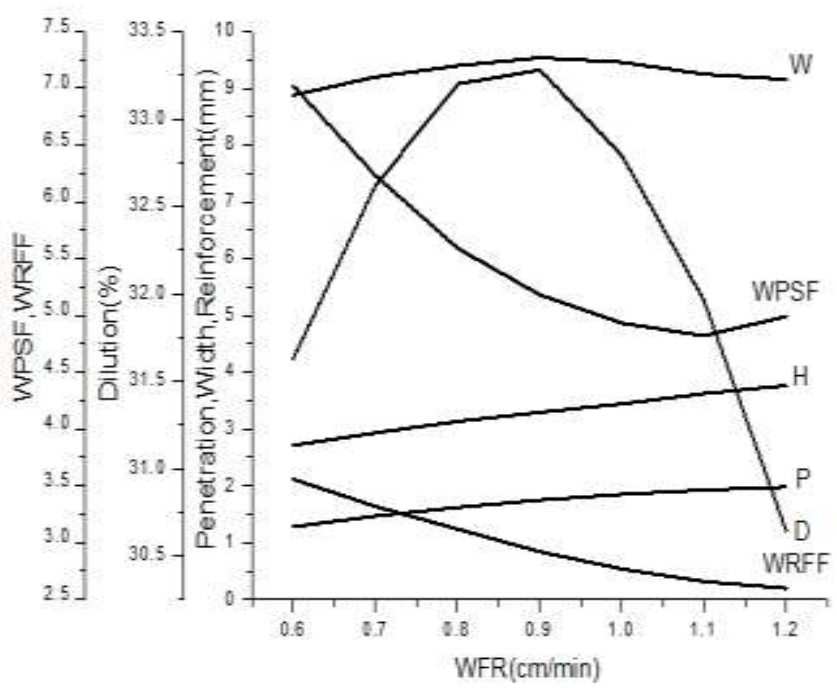

Fig 6: Direct effect of WFR

It is evident from the figure 6 that on increasing WFR, penetration increases linearly. This is probably as WFR and current have direct linear relation which leads to enhanced current density resulting in higher amount of melting of base metal which results in increases penetration. Height of reinforcement and width increases on increasing the WFR due to the piling effect of weld droplets on the metal piece.
Dilution first increases with increase in WFR as the increase in penetration area is greater than the total area whereas later there is a decrease in the dilution due to the greater rate of increase of the height and width than penetration, which results in greater total bead area,which hence decreases dilution. WPSF and WRFF decreased with increase in WFR because at higher values of current the rate at which penetration and reinforcement increased was higher than the rate at which width increased.

\subsubsection{Direct Effect of Welding Speed}

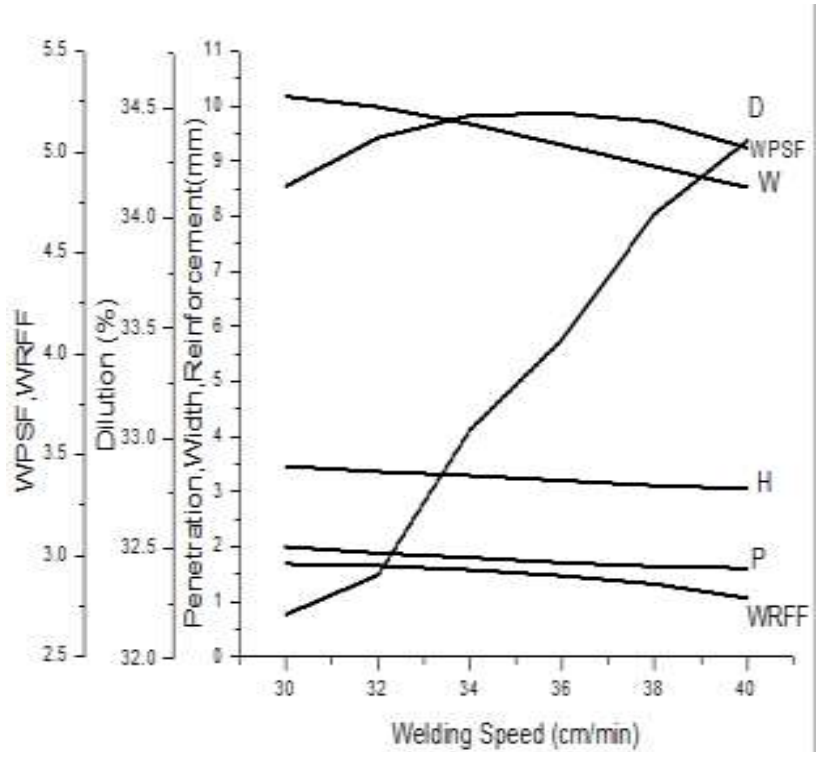

Fig 7: Direct effect of Welding speed

It is evident from the figure 7 that on increasing welding speed, penetration decreases. It is probably due to the fact that at higher values of welding speed, heat input per unit length decreases which results in less penetration. Similarly the same reason can be applied to the effect on weld bead width and height of reinforcement showing the similar trends. Dilution increased with the increase in welding speed as the decrease in the total weld area is greater than the decrease in the penetration area. WPSF and WRFF decreases with the increase in welding speed because the rate of decrease of width is higher than the rate of decrease in penetration and reinforcement. 


\subsubsection{Direct Effect of Nozzle to Plate Distance (NPD)}

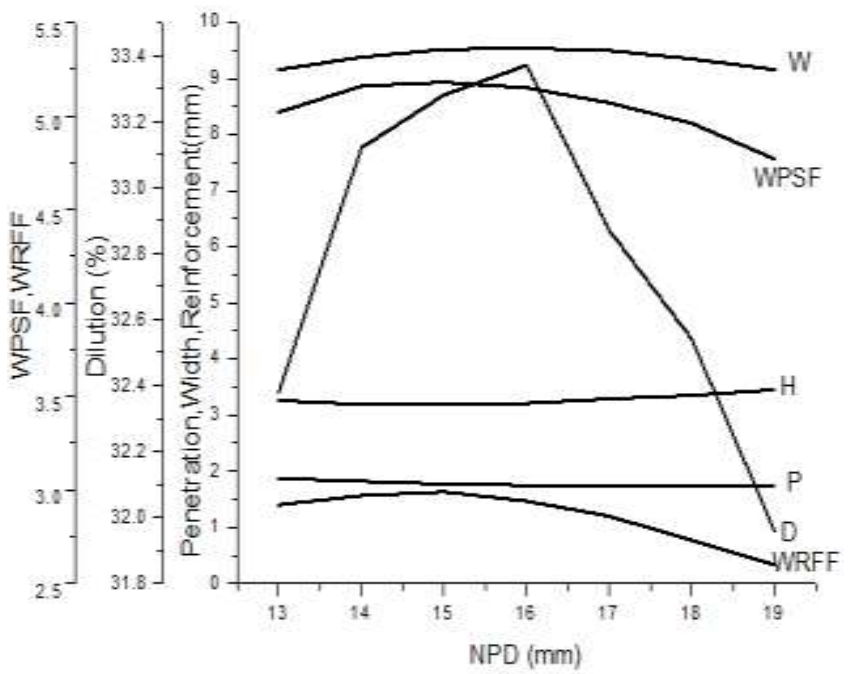

Fig 8: Direct effect of NPD

It is evident from the figure 8 that penetration decreased with increase in NPD. This is due to the preheating of wire which prevents the fusion of the weld droplet with the base metal. Similarly there is an increase in the height of reinforcement with increase in NPD due to piling effect.
Dilution first increased and then decreased because initially penetration is more dominant than piling effect and then there is greater rate of decrease in penetration area than the total bead area.WPSF and WRFF decreases with the increase in NPD this may be due to the fact that width decreases and there is insignificant change in penetration and height.

\subsubsection{Direct Effect of Torch Angle}

The investigative experimentation has revealed that effect of torch angle on response parameters is not significant within the selected working range of the same; therefore the discussion on this aspect is avoided.

\subsubsection{Interaction Effects of Input Parameters on Response}

During the experimental investigation of this kind it is found that the input parameters interact together to have an effect on the final output. The curvature in the surface plots indicate the presence of interaction effects. In the present study the interaction effects of two variables at a time are considered as the interaction effects of higher orders are found to be negligible and are of less industrial consequence

\subsubsection{Interaction Effect of Welding Speed (S) and Wire Feed Rate (WFR) on Penetration (P)}

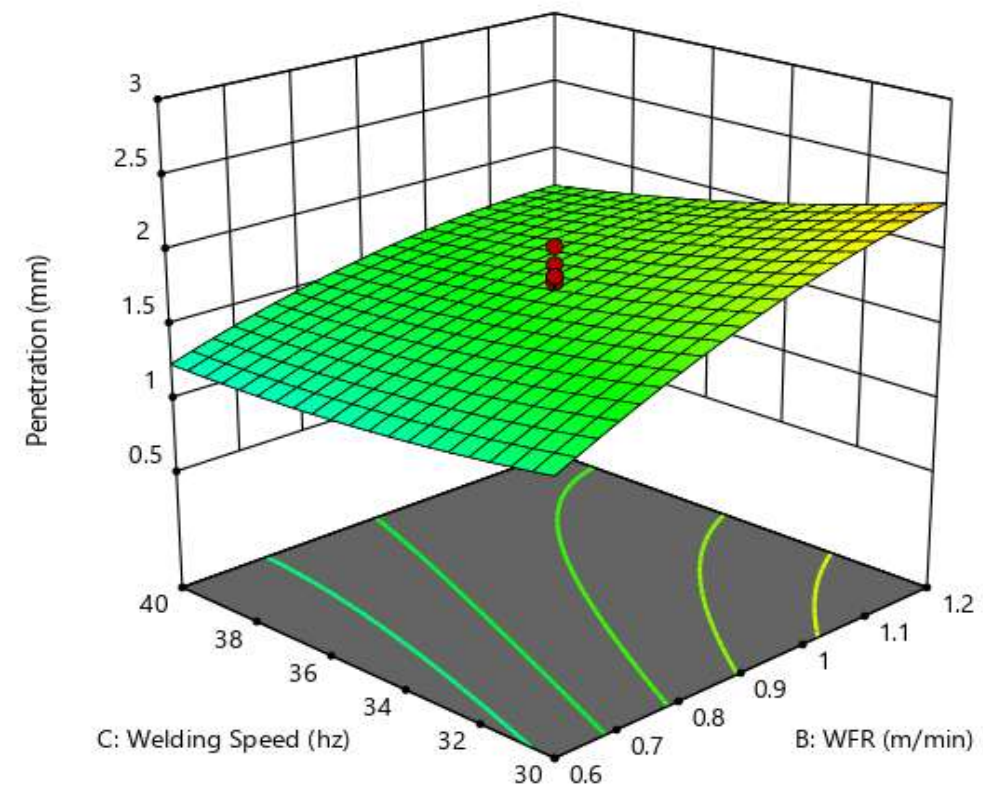

Fig 9: Ineraction Effect of Welding speed and WFR on Penetration

From the figure it is evident that value of penetration increased with the increase in WFR for all values of welding speed whereas penetration remains constant(insignificant change) for low range wire feed rates but decreases at higher values of wire feed rate with the increase in welding
speed.Thus the above graphical study revealed that WFR has positive impact on penetration and welding speed has negative impact on penetration as less time is available for heat to penetrate at higher welding speeds. 


\subsubsection{Interaction Effect of Welding Speed (S) and Voltage (V) on Weld Width (W)}

From the figure it is evident that on increasing voltage the value of weld width increases significantly for all values of welding speed whereas on increasing welding speed weld width decreases for all values of voltage. This may be due to the fact that increase in voltage spreads the arc thereby increasing the width.

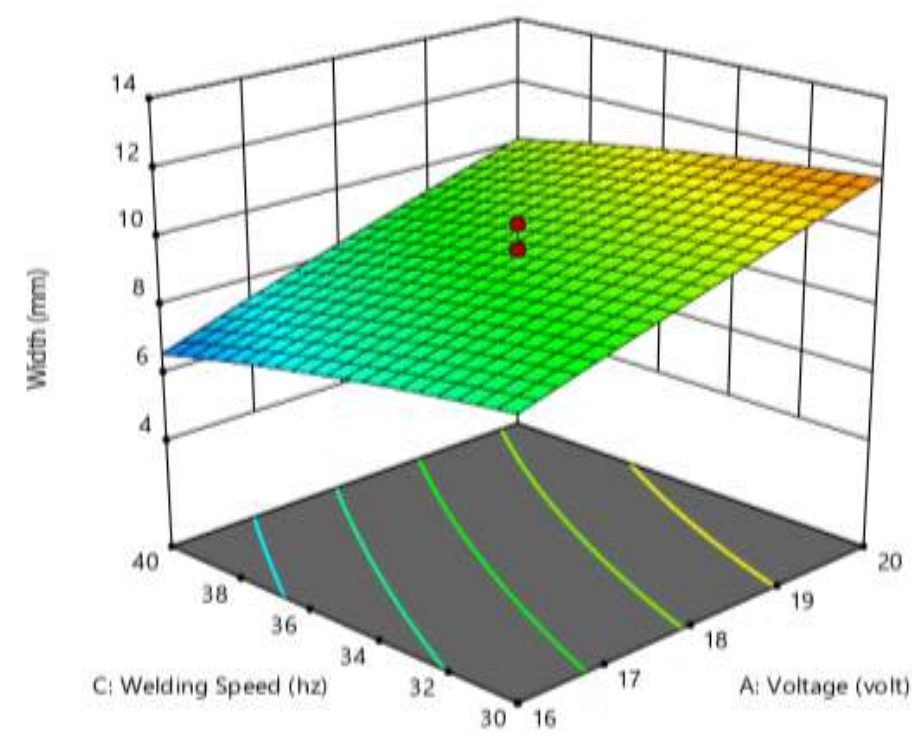

Fig 10: Ineraction Effect of Welding Speed and Voltage on Width

\subsubsection{Interaction effect of Wire Feed Rate (WFR) and Voltage (V) on Height of Reinforcement (H)}

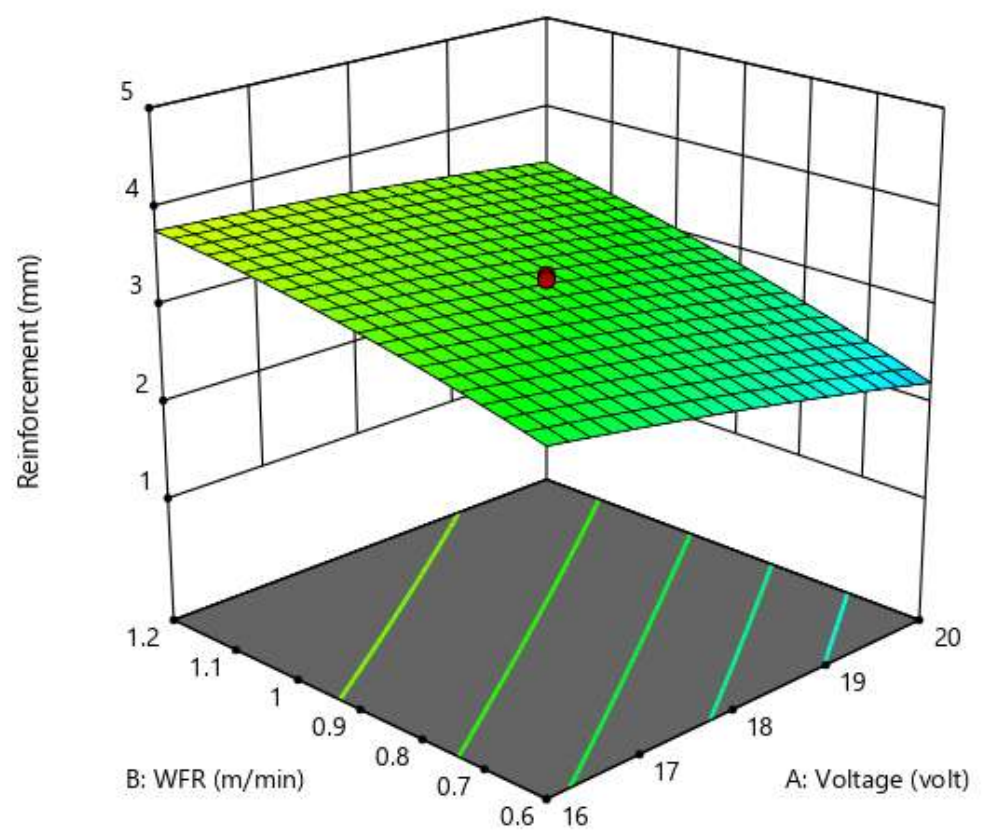

Fig 11: Ineraction Effect of WFR and Voltage on Height of Reinforcement

From the figure it is evident that on increasing WFR height of reinforcement increased for all values of Voltage whereas height of reinforcement decreased with the increase in voltage for all values of wire feed rate (WFR). The reason could be with the increase in voltage the bead has spreading tendency whereas with the increase in wire feed rate, metal piling effect increased. 


\subsubsection{Interaction Effect of Voltage (V) and Welding Speed (S) on Weld Dilution (D)}

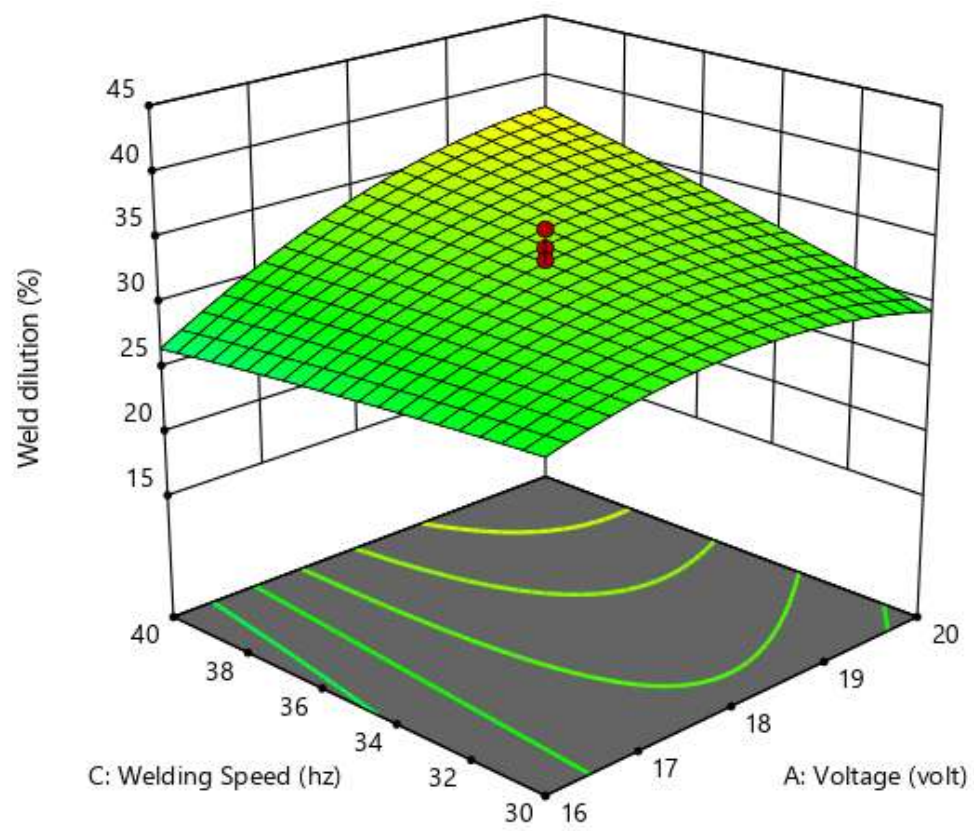

Fig 12: Ineraction Effect ofVoltage and Welding Speed on Weld Dilution

It can be seen that dilution is minimum at the minimum values of voltage and welding speed, whereas maximum dilution is obtained at maximum values of these parameters because of increased heat input

\subsubsection{Interaction Effect of Wire Feed Rate (WFR) and Voltage (V) on Weld Penetration Shape Factor (WPSF)}

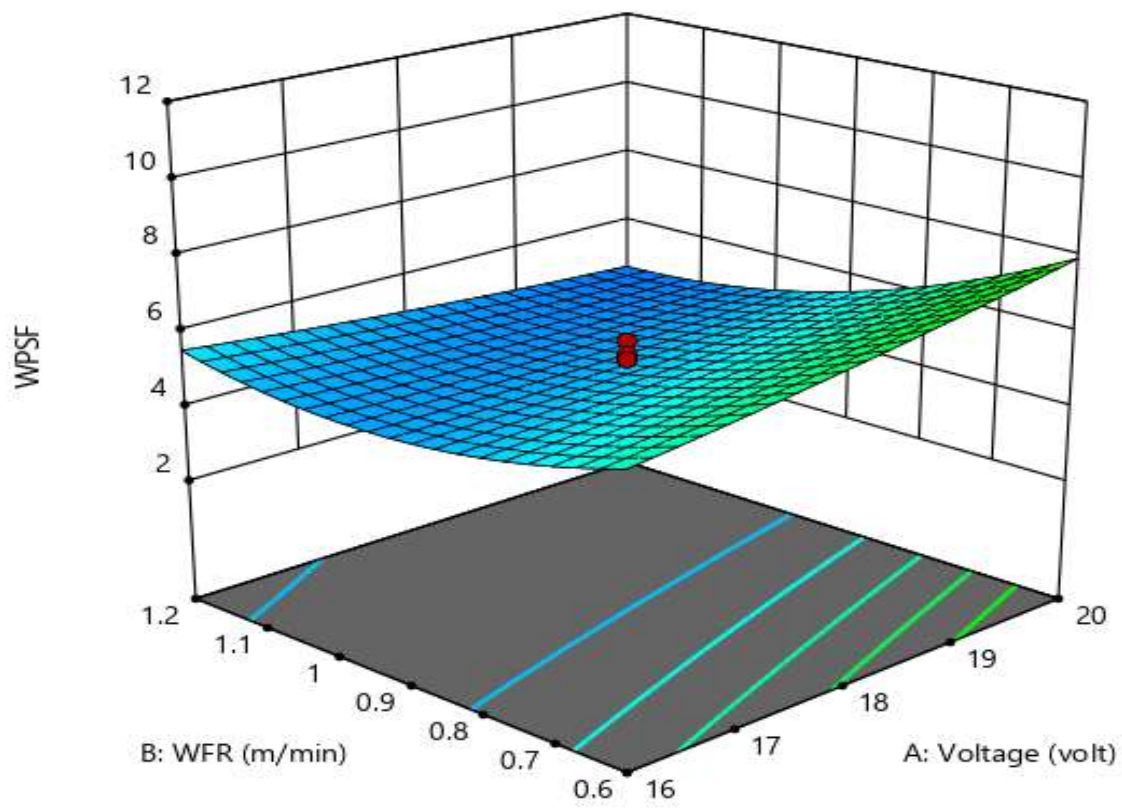

Fig 13: Ineraction Effect ofWFR and Voltage on WPSF

From the above figure it is evident that on increasing voltage, at low WFR, WPSF increased because of dominant increase in width as compared to depth. The trend however reversed at higher WFR because of the dominance of penetrating effect over width due to the higher values of WFR. 


\subsubsection{Interaction Effect of Voltage (V) and Wire Feed Rate (WFR) on Weld Reinforcement Form Factor}

\section{(WRFF)}

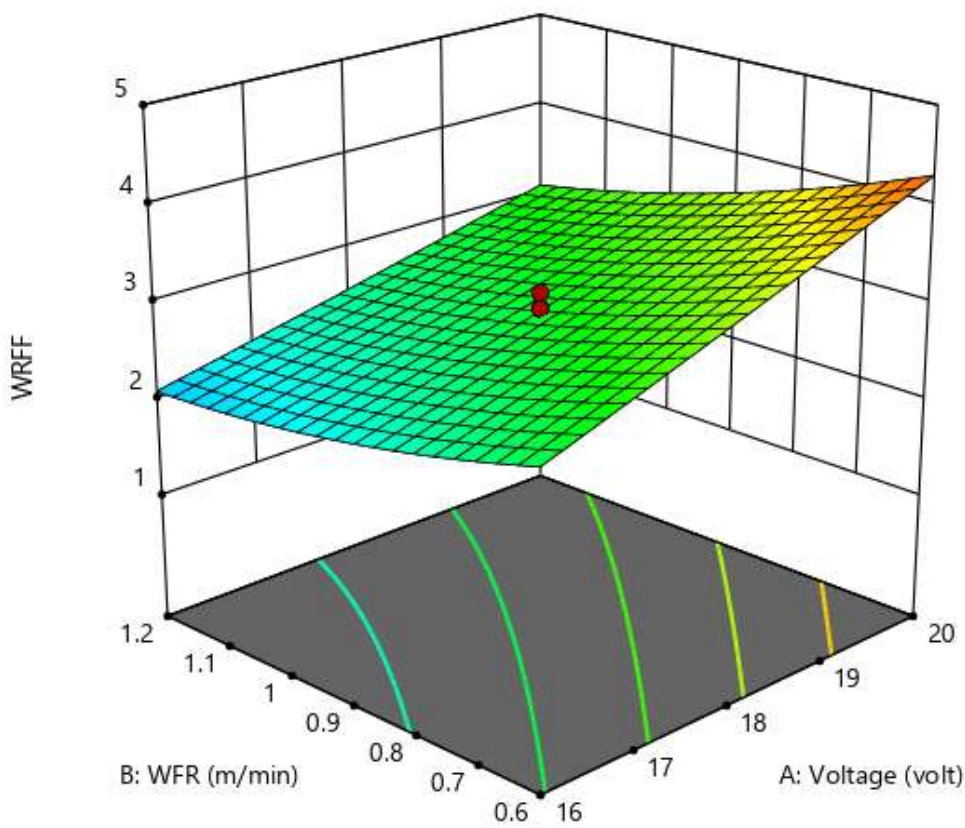

Fig 14: Ineraction Effect ofVoltage and WFR on WRFF

From the above figure it is evident that on increasing voltage, WRFF increases more rapidly at low WFR because with the increase in voltage the reinforcement height drops significantly. This trend however became less significant at higher WFR because of more metal piling effect.

\section{CONCLUSION}

1. The statistical technique of the central composite rotatable design has been proved to be useful in analyzing weld bead geometry.

2. The investigation of direct effects show that WFR has positive effect on penetration, width and reinforcement

3. Voltage has positive effect on width but negative effect on penetration and reinforcement

4. Welding speed has negative effect on penetration width and reinforcement

5. NPD is found to have positive effect on reinforcement and negative effect on width and penetration

6. Torch angle is found to have only nominal effects on output parameters.

7. Interaction effects of WFR and welding speed on penetration suggests that penetration is minimum at high values of welding speed and low WFR, whereas penetration is maximum at higher values of WFR and low values of welding speed.

8. Interaction Effect of Welding Speed and Voltage on Weld Width suggests that weld width is minimum at higher value of welding speed and lower value of volatge, whereas width is maximum at higher values of voltage and low values of welding speed

9. Interaction effect of Wire Feed Rate and Voltage on Height of Reinforcement suggests that reinforcement is minimum at higher values of voltage and lower value of WFR, whereas reinforcement is maximum at higher values of WFR and lower value of voltage.

10. Interaction Effect of Voltage and Welding Speed on Weld Dilution suggests that weld dilution is minimum at lower values of voltage and welding speed, whereas weld dilution is maximum at higher values of voltage and welding speed.

\section{REFERENCES}

[1] Benyounis, K. Y., Olabi, A.G., "Optimization of Different Welding Processes Using Statistical and Numerical Approaches- A reference guide", pp. 1-29

[2] Kamble, A. G., Rao R. V., Kale A.V., "Development of Mathematical Models for Prediction of Weld Bead Geometry for AISI 430 Grade of Steel for GMAW Welding Process". International Journal of Manufacturing Technology and Industrial Engineering (IJMTIE) Vol. 1, No. 1, pp. 1-6, January-June 2011.

[3] Ghosh, A., Hloch Sergej, "Prediction and Optimization of Yield Parameters for Submerged Arc Welding" 
[4] Brockenbrough R L., "Properties of Structural Steels and Effects of Steel making and Fabrication. Hand book for Structural Steel Design Chapter", McGrawHill Professional, Fourth Edition, 2006.

[5] Material Specification Sheet, Saarstahl AG, SHS Stahl-Holding-Saar GmbH \& Co. KGaA, pp. 1-2.

[6] Lee J. and Um, K., "A Prediction of Welding Process Parameters by Prediction of Back-Bead Geometry. Journal of Materials Processing Technology", 108(1), 106-113, 2000

[7] Rao, P.S., Gupta, O.P., Murty, S.S.N., "Influence of Process Parameters on Bead Geometry in Pulsed Gas Metal Arc Welding", IIW International Congress, Mumbai India, 2005.

[8] Rao P.Srinivasa, Gupta O.P., Murty. S.S.N, Rao ABK, "Effect of Process Parameters and Mathematical Model for the Prediction of Bead Geometry in Pulsed GMA welding", The International Journal of Advanced Manufacturing Technology, 45 (5-6), 496-505,2009.

[9] Kanti K.Manikya, Rao P.S., Rangajanrdhan, Rani AMA, "Mathematical Modeling for the Prediction of Depth of Penetration in Double Pulse GMA Welding Using Fractional Factorial Method", Applied Mechanics and Materials, 660, 347-351, 2014. 